\title{
Early infection and subsequent insulin dependent diabetes
}

\author{
Caspar Gibbon, Trevor Smith, Peter Egger, Peter Betts, David Phillips
}

\begin{abstract}
In a study of 58 children under the age of 16 with insulin dependent diabetes (IDDM) and 172 matched non-diabetic controls, infection during the first year of life was associated with a reduction in diabetes risk (odds ratio $0.81,95 \%$ confidence interval 0.67 to 0.98 , per infective episode). Decreased exposure to common infections during infancy may be linked with subsequent IDDM.

(Arch Dis Child 1997;77:384-385)
\end{abstract}

Keywords: insulin dependent (type 1) diabetes; infancy; infection; case-control study

Recent observations have suggested that reduced exposure to common microbial infections in early life may increase subsequent susceptibility to insulin dependent diabetes (IDDM). The 'hygiene' hypothesis ${ }^{1}$ has stemmed from observations in the diabetes susceptible $\mathrm{BB}$ rat and NOD mouse that disease frequency is maximised when the pups are raised in pathogen-free environments ${ }^{2}$ but is greatly decreased by viral infection or exposure to bacterial antigens in early life. ${ }^{34}$ The human evidence, however, is restricted to the evidence that IDDM is associated with factors which would tend to reduce exposure to infection in childhood such as low population density and small family size. ${ }^{5}$ To test the hygiene hypothesis we carried out a casecontrol study based on routinely recorded data on childhood infections obtained from general practitioners' records.

Metabolic

Programming Group, MRC Environmental Epidemiology Unit, University of

Southampton

C Gibbon

T Smith

P Egger

D Phillips

Department of Child Health, Southampton General Hospital

P Betts

Correspondence to: Dr D I W Phillips, MRC

Environmental Epidemiology Unit (University of

Southampton), Southampton General Hospital, Tremona

Road, Southampton

SO16 6YD.

\section{Methods}

We ascertained all children under the age of 16 with IDDM resident in the Southampton and South West Hampshire Health District

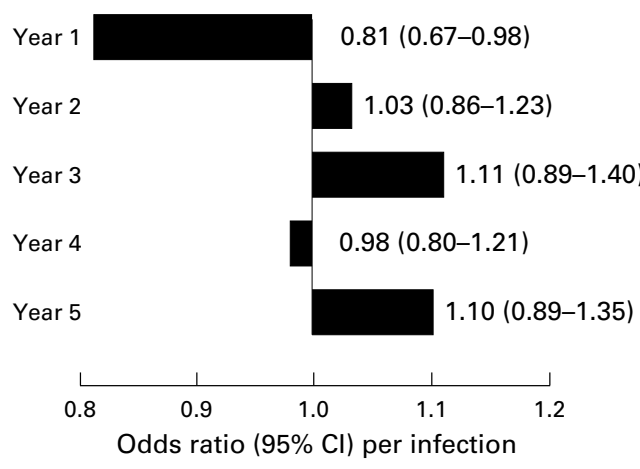

Figure 1 Alteration in the OR of IDDM per infective episode calculated for each of the first five years of life. between 1 October 1992 and 30 September 1993. As the paediatric diabetes service is centralised, the principal source of information was the case records of the paediatric diabetic clinic at Southampton General Hospital. To ensure completeness of ascertainment, we asked paediatricians in adjacent health districts if they knew of any Southampton children with IDDM not known to us. They did not. Each case was matched with three controls of the same sex and birth year randomly selected from the list of the attending general practitioner. Consultations for infections during the first five years of life were systematically recorded from the case records, together with the date of attendance and details of prescribed drugs. The social class at birth was based on the father's occupation. Records were located for 58 of the 60 cases and 172 of the 180 controls: for the remainder, the subjects had either moved or the notes were incomplete. Relative risks were estimated by the odds ratios (OR) and $95 \%$ confidence intervals (CI) calculated by conditional logistic regression for matched sets. Values are given as mean (SD).

\section{Results}

The children with IDDM (26 boys and 32 girls) were aged 10.5 (SD 3.8) years and were diagnosed at a mean of 7.9 (SD 3.9) years. The average number of infections reported per child fell from 2.35 in the first year of life to 1.36 in the fifth year. Figure 1 shows that infections had a protective effect during the first year of life (OR 0.81 (95\% CI 0.67 to 0.98) per infective episode) but not during the remaining four years. The protective effect was observed in both genders (OR in boys 0.79 (0.61 to 1.02 ) and in girls 0.86 (0.69 to 1.08$)$ ); and was most apparent among cases diagnosed under the age of 6 (OR 0.61, CI 0.40 to 0.93). Inclusion of social class at birth (available for $67 \%$ of cases and $64 \%$ of controls) as an independent variable in the regression made little difference to the OR (0.79, CI 0.60 to 1.04$)$. Analysis by category of infection suggested that respiratory infections, which accounted for $52 \%$ of the reported infections in the first year of life, had the most marked protective effect (OR 0.68, CI 0.49 to 0.92).

\section{Discussion}

The general practitioner's record is an imperfect source for ascertaining data on infections. Clearly mothers are unlikely to consult their doctors for all childhood infections and the doctors may fail to record 
surgery consultations accurately. Thus the number of infections recorded in this study will have underestimated the true number of infectious episodes experienced by the children. However, it is unlikely that this has biased our study. Cases were closely matched with controls attending the same general practitioner in order to minimise systematic differences between cases and controls both for access to the general practitioner and the diagnostic accuracy of the records.

The results of this study suggest that children who develop IDDM spent their infancy in conditions associated with a decreased risk of common infections. The results are in accord with a Scandinavian study which found a similar trend concerning infection during the first year of life, although this did not reach statistical significance. ${ }^{6}$ Infection during the first year may have a protective effect by modifying the lymphocytic response to subsequent immunological challenge, as has been shown in the BB rat. ${ }^{3} \mathrm{~A}$ link with decreasing early exposure to common infectious diseases could account for the rise in incidence of diabetes observed in many northern European countries over the past 30 years.

1 Kolb H, Elliott RB. Increasing incidence of IDDM a consequence of improved hygiene? Diabetologia 1994;37:729-31.

Leiter EH, Serreze DV, Prochazka M. The genetics and epidemiology of diabetes in NOD mice. Immunol Today 1990; 11:147-9.

3 Schwimmbeck PL, Dryberg T, Oldstone MBA. Abrogation of diabetes in BB rats by acute virus infection. Association of viral-lymphocytic interactions. I Immunol 1988;140: of viral-lym

4 Wilberz S, Partke HJ, Dagnaes-Hansen F, Herberg L. Persistent MHV (mouse hepatitis virus) infection reduces the incidence of diabetes mellitus in non-obese diabetic mice. Diabetologia 1991;34:2-5.

5 Patterson CC, Carson DJ, Hadden DR. Epidemiology of childhood IDDM in Northern Ireland 1989-1994: low incidence in areas with highest population density and most household crowding. Diabetologia 1996;39:1063-9.

6 Blom L, Dahlquist G, Nystrom L, Sandstrom A, Wall S. The Swedish diabetes study - social and perinatal determinants for diabetes in childhood. Diabetologia 1989;32:7-13. 